\title{
Immune System Evasion as Hallmark of Melanoma Progression: The Role of Dendritic Cells
}

\author{
Marco Tucci ${ }^{*}$, Anna Passarelli ${ }^{\dagger}$, Francesco Mannavola, Claudia Felici, \\ Luigia Stefania Stucci, Mauro Cives and Francesco Silvestris \\ Department of Biomedical Sciences and Human Oncology, University of Bari Aldo Moro, Bari, Italy
}

Melanoma is an immunogenic tumor whose relationship with immune cells resident in the microenvironment significantly influences cancer cell proliferation, progression, and metastasis. During melanomagenesis, both immune and melanoma cells undergo the immunoediting process that includes interconnected phases as elimination, equilibrium, and escape or immune evasion. In this context, dendritic cells (DCs) are active players that indirectly counteract the proliferation of melanoma cells. Moreover, DC maturation,

OPEN ACCESS

Edited by:

Ignacio Melero,

University of Navarra, Spain

Reviewed by:

Natalia Aptsiauri,

University of Granada, Spain

Augusto C. Ochoa

Louisiana State University,

United States

${ }^{*}$ Correspondence:

Marco Tucci

marco.tucci@uniba.it

${ }^{\dagger}$ These authors have contributed equally to this work

Specialty section

This article was submitted to Cancer Immunity and Immunotherapy,

a section of the journal

Frontiers in Oncology

Received: 15 May 2019 Accepted: 16 October 2019 Published: 05 November 2019

Citation:

Tucci M, Passarelli A, Mannavola F,

Felici C, Stucci LS, Cives M and Silvestris $F$ (2019) Immune System Evasion as Hallmark of Melanoma

Progression: The Role of Dendritic

Cells. Front. Oncol. 9:1148.

doi: 10.3389/fonc.2019.01148 migration, and cross-priming as well as their functional interplay with cytotoxic T-cells through ligands of immune checkpoint receptors result impaired. A number of signals propagated by highly proliferating melanoma cells and accessory cells as T-cells, natural killer cells (NKs), tumor-associated macrophages (TAMs), T-regulatory cells (T-regs), myeloid-derived suppressor cells (MDSCs), and endothelial cells participate to create an immunosuppressive milieu that results engulfed of tolerogenic factors and interleukins (IL) as IL-6 and IL-10. To underline the role of the immune infiltrate in blocking the melanoma progression, it has been described that the composition, density, and distribution of cytotoxic T-cells in the surrounding stroma is predictive of responsiveness to immunotherapy. Here, we review the major mechanisms implicated in melanoma progression, focusing on the role of DCs.

Keywords: melanoma, dendritic cells, microenvironment, checkpoint inhibitors, T-cells

\section{INTRODUCTION}

Cutaneous melanoma (CM) is an aggressive cancer that arises from melanocytes originating from the neural crest. These cells then migrate into the epidermis, where they undergo maturation and acquire the ability to produce melanin. The incidence of CM has increased worldwide during the last several decades, with a higher prevalence in males and younger adults (1). It frequently arises from chronically sun-damaged skin and is characterized by a high mutational load. The genetic landscape in CM includes many different driver and passenger gene mutations implicated in tumor cell survival and proliferation $(2,3)$.

During melanomagenesis, tumor cells interact with components of the immune system, whose functional activity is directed at preventing melanoma progression and metastasis (4). Although lymph node metastasis and Breslow thickness are still considered negative prognostic predictors (5), the propensity of melanoma cells to invade distant tissues also depends on their interaction with cells of the tumor microenvironment (TME) and the efficiency of the immune response. The characteristics of tumor-infiltrating lymphocytes (TILs) surrounding melanoma cells influence 
the prognosis while their localization, composition, and density positively correlate with survival and decreased risk of metastasis (6). In this context, both $\mathrm{CD}^{+}$and $\mathrm{CD}^{+}{ }^{+} \mathrm{T}$ cells represent the prevalent immune infiltrating populations found nearby melanoma cells but recent studies revealed that the presence of other molecules may potentially correlate with prognosis as the loss of expression of p16, the switch of the M2/M1 polarization of macrophages and the levels of immune checkpoints including PD-1 and VISTA (V-domain Ig suppressor of T-cell activation) (7-9).

The results of immunotherapy studies in murine melanoma models have given rise to a "cancer immune surveillance hypothesis," which postulates the continuous activity of dendritic cells (DCs) in tumor cell recognition and elimination (10). Anticancer immunity consists of a sequence of functional events, referred to as the immunity cycle, whose disruption allows cancer cells to overwhelm immune system control (11, 12). Among the mechanisms allowing melanoma cells to escape immune system control are the release of immune suppressive cytokines within the TME and the up-regulation of inhibitory checkpoints on T-cells (13). The defective immunity that characterizes CM depends on derangements in both the cytotoxicity of T-cells and the function of DCs. Accordingly, manipulation of the cellular components of the immune system may be a promising therapeutic strategy in CM.

The $\mathrm{CD}_{3}{ }^{+}$progenitor cells of DCs resides in the bone marrow, where they differentiate into specialized subsets differing in their maturation, activation and co-stimulation (14). These differentiated DCs circulate in peripheral blood while migrate to lymphoid and peripheral tissues, where they regulate both innate and adaptive (15-17), but are also able to migrate toward the TME. The critical aspects of the functional activity of DCs in various cancers, including CM, are their ability to capture foreign antigens and the efficiency of cross-priming (18). Previously, DCs were considered to be either conventional or classical DCs (cDCs), providing stimulatory functions, or tolerogenic plasmacytoid DCs (pDCs) (19). However, this classification has been recently revised based on the recognition of the plasticity of these populations, whose behavior is apparently influenced by soluble factors produced by melanoma cells $(20,21)$. In addition to pDCs, myeloid DCs (mDCs) are now recognized to differ in their phenotype, migratory capacity and their response to chemotactic stimulation, chemokine repertoire, and morphology. The level of circulating mDCs was shown to correlate with melanoma activity and the detection of these cells in patients at high risk of recurrence may reflect the persistence of malignant cells within the pre-metastatic niche (22). However, in addition to this pathway of melanoma progression, many others have been recently explored and thus usable in immunotherapy. For example, melanoma cells may also overcome immune system control through the production of negative mediators as transforming growth factor (TGF)- $\beta$, the activation of metabolic pathways such as either indolamine 2,3-dioxygenase (IDO) or CD39/CD73 axis and, lastly, the overexpression of negative immune checkpoint receptors by T-cells and related ligands (23). This phenomenon is defined as immune exhaustion or anergy and is characterized by a progressive loss of the immune activity.
To this regard, some of these negative immune checkpoints bind ligands expressed by mature DCs.

\section{DENDRITIC CELL SUBSETS AND THEIR ROLE IN MELANOMA IMMUNE INFILTRATE}

Dendritic cells originate from a bone marrow-derived population and circulate in blood and peripheral tissues where drive the innate immune response by processing antigens to naïve T-cells (24). Different types of specialized DCs have been described in mouse and humans, and the cellular or molecular mechanisms regulating their interaction with T-cells are at present partially known. Thus, the deep knowledge of different DC subsets requires the adoption of a dedicated nomenclature (25). In this context, a functional taxonomy distinguishes "DCs resident in lymph node" from "migratory tissue DCs" while a recent classification is codified in relation to the transcription factors' expression as interferon regulatory factor (IRF)-8, and IRF-4 (26). Therefore, pDCs and two types of cDCs have been described, the latter corresponding to the previously characterized subset of humans mDCs that also bear CD141 and CD1c antigens (27). Although cDCs and mDCs conventionally include a unique population, they substantially differ in terms of antigenic profile. Based on the most recent findings, specialized subsets of DCs may be indeed classified as pDCs, $\mathrm{cDC} 1$ and cDC2, Langerhans cells (LCs), monocyte-derived DCs (MoDCs), and small groups of cells including pre-DCs and nonclassical monocytes.

Plasmacytoid DCs have been largely investigated and typically produce large amounts of interferons and cytokines, thus resulting implicated in viral infection and cancer, including CM. These cells retain the CD123, CD303, and CD304 expression while do not express myeloid antigens. They circulate in peripheral blood and migrate toward peripheral sites whose accumulation may resemble as prognostic marker in melanoma (28). Myeloid $\mathrm{CDC} 1$ and $\mathrm{CDC} 2$ show a unique antigenic repertoire but $\mathrm{cDC} 1 \mathrm{c}$ are characterized by an intrinsic ability to present antigens through the class-I MHC for the stimulation of T-cells and both drive the Th1 polarization and promote the activation of NKs. Furthermore, human cDC1 express the chemokine CXCL9 and CXCL10 and secrete type-III interferon (IFN) and IL-12. By contrast, CDC2 are characterized by high levels of XCR1 chemokine receptor by which that permits their crosstalk in the TME with XCL-producing cells and NKs (2931 ). In addition, $\mathrm{cDC} 2$ produce cytokines as IL-12, IL-23, IL-1, IL-8, and IL-10 while modest is the capacity to secrete typeIII IFN. In mice, cDC1 have been also characterized as cells exerting tolerogenic functions but this role has not definitely proven in humans. However, cDC2 cells are the prevalent population in human blood and they express typical markers of myeloid differentiation, whereas a variable sensitivity to different transcription factors has been demonstrated in relation to their murine or human derivation. Both subsets of $\mathrm{cDCs}$ produce large amounts of cytokines by which they modulate the immune response. With respect to the $\mathrm{CM}$ microenvironment, the basal 
epidermis and stratified squamous epithelia are engulfed of LCs showing high levels of C-type lectin langerin as well as E-cadherin, EpCAM and claudin by which those cells closely interact with the epithelial layer (32). LCs are characterized by high migratory behavior to the skin-draining lymph nodes and are mostly accumulated nearby the T-cells enriched tumor area. Another group of DCs involved in the regulation of immune response includes those derived from monocytes (Mo-DCs) that can be identified in relation to the expression of myeloid markers and high production of IL-1, IL-12, and IL-23 (33).

In the context of melanoma, DC subsets modulate the Tcell activation and their defects are strongly correlated with clinical worsening related to the melanoma progression. Apart from the amounts of DCs that circulate in the peripheral blood, they usually surround the tumor cells in the TME forming the so-called immune infiltrate that is considered an indicator of responsiveness to immunotherapy (34). The efficacy of immunotherapy is, however, limited to a subset of patients. The anti-tumor activity of TME is exerted by T-cells but is also dependent on $\mathrm{CDC} 1$ and $\mathrm{cDC} 2$ activity, while the efficiency is correlated to the ability of these cells to present tumor-associated antigens and to produce cytokines implicated in the control of either survival or cytotoxic activity of T-cells. However, the cDC1 subset is extremely rare in humans although its levels strongly correlate with prognosis and responsiveness to immunotherapy. It has been also reported that $\mathrm{CDC} 1 \mathrm{~s}$ may expand through the transcription factor Batfl3 and express differential molecules as CD103 in murine or BDCA-3 in human melanoma (35). Further studies have demonstrated that the abundance of $\mathrm{cDC} 1 \mathrm{~s}$ surrounding tumor cells and their activity directly depend on the expression of the gene encoding Fms-related tyrosine kinase3 ligand (FLT3LG) whose intra-tumoral production is regulated by NKs $(34,36)$. Moreover, the recruitment of cDC1s in TME is also driven through CCR5 signals activated by intra-tumoral CCL5 transcripts whose levels correlate with gene signature of $\mathrm{NKs}$ and $\mathrm{cDC1}$ s as well as with increased overall survival (OS). On the other hand, prostaglandin-E2 produced by melanoma cells restrains the NK-cDC1 axis by impairing their viability and the chemokine production as well as by down-regulating the expression of CCR5 on CDC1s (37-39).

In conclusion, the immune infiltrate in terms of cells and soluble factors is a relevant indicator for early identification of good responders to immunotherapy, but also suggests that other receptors expressed by immune cells could be druggable in CM.

\section{THE TRIPLE-E AND IMMUNE SYSTEM-MELANOMA INTERACTION: ELIMINATION, EQUILIBRIUM AND ESCAPE}

Dendritic cells are critical to the activation of the adaptive immune system, based on their ability to migrate toward peripheral sites, where they are involved in the surveillance of antigens expressed by cancer cells. Stimulated by the melanoma, DCs mature and migrate to lymphoid tissues, where they interact with effectors of the immune response, including Tand B-cells as well as natural killer cells (NKs) $(17,40)$. DC maturation and efficient cross-priming are regulated by the interaction of the T-cell receptor (TCR) with molecules of the major histocompatibility complex (MHC) as well as the binding of CD80/86 with the T-cell stimulator CD28 or with the negative regulator CTLA-4, mostly within the lymph nodes (41) or by cytokine-induced signals and a specific chemokine profile $(42,43)$.

In $\mathrm{CM}$ and other immunogenic cancers, the altered recognition and elimination of malignant cells by the immune system has given rise to the concept of cancer immunoediting, which groups the interactions between (44) the immune system and cancer cells into distinct elimination, equilibrium, and escape phases required for the priming of an anti-melanoma response (12).

\section{Elimination}

During this phase, either innate or adaptive immunity attempts to eradicate the tumor cells, which are not yet clinically detectable. Effectors of the innate immune response include NKs, NK-T cells and $\gamma \delta$ T-cells, which are responsible for TME remodeling (45) and are stimulated by interleukins (ILs) produced by melanoma cells, tumor-associated macrophages (TAMs), and stromal cells. In addition, the over-production of cytokines stimulates both the inflammatory response and the recruitment of immune cells to induce the apoptosis of melanoma cells, leading to the release of new antigens that stimulate the adaptive immune response. During this phase, both maturation and DC homing to lymph nodes occur, resulting in the enhancement of antigen presentation and the formation of tumor-specific naive T-cells. Recruitment of these cells into the tumor bed drives the killing of melanoma cells by enhancing interferon (IFN)- $\gamma$ release and the induction of apoptosis through perforin, TRAIL and Fas-L as well as the inhibition of angiogenesis. However, the inflammation that potentially takes part in the DC maturation may, conversely, facilitate the tumor progression through signals driven by IL-10 and TGF- $\beta$ which are also major effectors of regulatory T-cells (Treg) development $(46,47)$.

\section{Equilibrium}

Over time, cancer cells develop resistance to effector immune cells via the selection of clones with limited immunogenicity (48). This accounts for the ability of melanoma cells to survive even in an immune-competent host. Moreover, melanoma cells may harbor a number of somatic mutations that not only support their rapid proliferation, but also enhance their genetic instability, thereby favoring the development of less immunogenic clones with a strong propensity to expand within the TME (49). Thus, the equilibrium phase consists of a chronic attempt by the immune system to eliminate tumor cells, mostly by the release of high levels of IFN- $\gamma(50)$.

\section{Escape}

The majority of malignant cells are eliminated during the equilibrium phase but new variants may emerge with mutations that increase the resistance to immune system control (44) and therefore promote cancer cell proliferation. Immune system escape includes alterations in the expression of signal 
transduction molecules on effector cells, the production of soluble factors by melanoma cells, the induction of immune-cell tolerance, a loss of the signal transducer CD3- $\zeta$, variability in the expression of the tumor antigen repertoire and the polarization of $\mathrm{T}$ helper-1 (Th1) cells (51). Among the tumor-derived soluble factors that contribute to immune cell suppression are vascular endothelial growth factor (VEGF), tumor necrosis factors (TNFs), TGF- $\beta$, IL-1, IL-6, IL-10, prostaglandin E2 (PGE2), Fas, and Fas-L. VEGF inhibits DC maturations via Stat-3 transcription and regulates both the recruitment of TAMs, Tregulatory cells (T-regs), and myeloid-derived suppressor cells (MDSCs) (52, 53). These soluble factors create a favorable environment to support tumorigenesis by increasing the cancer cell proliferation, angiogenesis, metastasis as well as exerting a direct effect on DC maturation that, at least in part, contribute to enhance the immune suppression. In this context, IL-6 is central in melanoma development and also enhances the IL10 production via STAT-3-dependent signaling (54). Apart from interleukins, the melanoma microenvironment is also engulfed of prostanoid including PGs. Among PGs, the PGE2 plays an exclusive role in tumor development, progression and metastasis directly acting on both tumor cells and stromal compartment. However, many studies focusing the role of PGE2 in cancer are not conclusive but a clear evidence of its effect in driving tumor progression has been demonstrated in BRAFV600E mutant murine melanoma model $(55,56)$.

Besides soluble factors released by tumor cells, deregulated antigen processing and presentation are relevant events promoting the melanoma progression. The impaired immune response is mostly attributable to either a defective activity of DCs or the reduced cytotoxicity mediated by $\mathrm{CD}^{+}$T-cells $(52,53)$. In addition, the heterogeneity of the antigenic repertoire is a peculiar feature of melanoma cells and a requisite for evading the immune system control (57). Antigens are displayed to $\mathrm{CD}^{+}$cells through presentation as part of the major histocompatibility class-I (MHC-I) complex on the membranes of melanoma, immune, and accessory cells infiltrated within the microenvironment. This event is to be considered a portrait of the melanoma milieu for activated $\mathrm{CD}^{+} \mathrm{T}$-cells. In this context, highly proliferating melanoma cells reduce the visibility of MHC-I to cytotoxic cells and many studies in cancer models, including melanoma, reported an association between loss of MHC-I activity and survival. The mechanisms favoring the MHC masking to effector T-cells include (a) genetic and epigenetic modifications; (b) altered activity of the immunoproteasome including the three subunits formed by low molecular weight polypeptides (LMPs), namely LMP-2, LMP-7, and LMP-10. The proteasome is responsible for the turnover of proteins while LMPs provide the optimal anchor residue for stable binding to MHC-I; (c) reduced activity of the transporter associated with antigen processing (TAP) whose activity consists in the efficient transport of peptides into the endoplasmic reticulum and their loading onto MHC-I complex; (d) low expression of the chaperone calnexin, calreticulin (CRT), ERp57, and the peptide editor tapasin that serves as bridge between MHC-I, TAP, and CRT. These alterations have been demonstrated in melanoma, lung, prostate, and ovarian cancer and result variably implicated in the inhibition of those processes that regulate the antigen capturing and presentation that result impaired in cancer $(58,59)$. In addition, tumor cells are surrounded by infiltrating lymphocytes and macrophages whereas there is compelling evidence that the amounts of immune cells infiltrating tumor cells correlate with survival in breast, colon, and pancreatic cancer as well as melanoma. Moreover, as part of the immunoediting process, the degree of intra-tumoral MHC-I down-regulation directly correlates with both type and density of infiltrating immune cells, macrophages as well as levels of IFN- $\gamma(60-63)$.

\section{DENDRITIC CELLS AND THE MELANOMA MICROENVIRONMENT \\ Dendritic Cells and Role of TLRs}

As the most potent professional antigen-presenting cells (APCs), DCs are critically involved in the capture and presentation of tumor antigen to naïve T-cells and thus in immune surveillance. The generation of an efficient immune response by DCs requires their active mobilization in response to specific gradients generated in distant tissues and their intra-nodal migration. Immune stimulation is driven by the ability of DCs to engulf cargo molecules in vesicles and exosomes, which results in the release of the molecular signals that induce immune system activity $(64,65)$. Among the early events required for the activation and migration of DCs are the over-expression of CC-chemokine receptor-7 (CCR7), whose binding with CCL21 guides DCs into the lymphatic vessels through haptotaxis (66, 67). CCR7 expression is under the control of the transcriptional activator nuclear factor-kB (NF-kB) $(68,69)$. Once inside the lymphatic vessels, DCs migrate first to the subcapsular sinus and then into the lymph node parenchyma. The lower basement membrane of the subcapsular sinus is enriched in T-cells, the recruitment of which is favored by structural modifications induced by DCs through the interplay of CCR8/CCL21 and Lselectin (70-72). The different subsets of cDCs found in the dermis include $\mathrm{XCR} 1^{+}, \mathrm{CD} 11 \mathrm{~b}^{+}$and XCR $1^{-} / \mathrm{CD} 11 \mathrm{~b}-\mathrm{DCs}(73$, 74 ) as well as CCR2 ${ }^{+}$monocyte-derived DCs.

In $\mathrm{CM}$, however, impaired DC maturation, the defective expression of CD80 and CD86 co-stimulatory molecules and the up-regulation of CTLA4 or PD-1 receptors (75) result in clinical progression of the disease. Langerhans cells, a subset of APCs localized in the epidermis, are affected by melanoma progression as well, including their immune activity and number (76). While normally anchored to keratinocytes by Ecadherin, LCs acquire motility under the influence of TGF- $\beta$ and thus promote melanoma progression via immune suppression, including peripheral tolerance, the expansion of Tregs and the stimulation of IL-10 production in the TME. Like cDCs, LCs respond to CCR7 by migrating to lymph nodes; however, they accumulate in the deep paracortex whereas cDCs localize to the interfollicular space.

Another critical property of DCs for the discrimination of non-self antigens is represented by pattern-recognition receptors that include the family of toll-like receptors (TLRs). Thirteen 
different TLRs have been described in mammals although only 10 out of them are encoded in the human genome (TLR1-10). An implication of TLRs in DC biology includes their activity as defensive barrier by the recognition of microbial components as microbe, pathogen-associated molecular patterns (MAMPs, PAMPs), and damage-associated molecule patterns (DAMPs) (77). In addition, the DC interaction with TLR ligands induces the production of type-I IFNs and other pro-inflammatory cytokines within the TME. This interplay also promotes the DC maturation and enhances their antigen presentation ability to naïve T-cells, thus resulting in effective activation of the adaptive immunity.

However, the pattern of TLR expression differs among the DC subsets. In fact, pDCs mostly express both TLR7 and TLR9, whereas cDCs are TLR1-7+ ${ }^{+}$but negative for TLR9. Moreover, these cells produce several cytokines in response to TLR ligands and, as previously demonstrated, high levels of type-I IFNs are produced by pDCs stimulated with TLR7 or TLR9 ligands, while cDCs release IL-12 following the interaction with TLR7, TLR8, and TLR4 ligands. Indeed, further evidence suggest that the stimulation of TLR2 ${ }^{+}$DCs by tumor-derived TLR 2 ligands drives inhibitory signals leading to dysfunctional activity of DCs in murine melanoma (78). On the other hand, activation of TLR2 ${ }^{+}$ DCs inhibits the immune responsiveness of TME through the release of IL-10 and IL-6, while DC themselves may suffer of an autocrine negative effect exerted by the upregulation of both IL-6 and IL-10 receptors. Further studies have shown that TLR2 enhances the immune suppression by stimulating the MDSCs survival, thereby restraining the anti-tumor T-cell activity (79).

The increasing knowledge regarding the effects mediated by the activation of TLRs on DCs is a requisite for the development of TLR agonists. In this context, they have been investigated in pre-clinical models and clinical trials, thus revealing a potential role as adjuvants for the anti-cancer immunotherapy (80). In this context, Imiquimod is a TLR-7 agonist used for the treatment of skin disorders including basal cell carcinoma. It shows structural similarity with the adenosine nucleotide analog and thus may inhibit the Hedgehog signaling by stimulating the adenosine receptor. In addition, the Bacillus CalmetteGuerin (BCG) is a well-known TLR agonist exerting activity on TLR2, TLR4, and TLR9 in bladder cancer. These findings have leaded the basis for the development of many translational and pre-clinical studies in different cancer models including metastatic melanoma. In particular, a TLR3 agonist has been used in patients suffering of myeloid acute leukemia leading to a functional restoration of the immune system activity. Moreover, a TLR4 agonist (GSK1795091) has been tested in phase-I trial, whereas Imiquimod followed by bevacizumab received the FDA (Food and Drug Administration) approval in refractory glioblastoma. Other studies demonstrated that the combination of a TLR3 agonist (ARNAX) with a PD-L1 blocker might overcome the resistance to anti-PD-1 treatment (75). To this regard, a promising role is played by TLR9 agonists (CMP001, SD-101) that have been recently investigated in refractory metastatic melanoma patients for overcoming the acquired resistance developed to anti-PD1 blockers, thus leading to local and systemic effects or turning the immunologically "cold" to "hot" tumor (80). Furthermore, basic researches suggested the interplay of TLR-mediated signaling with the local metabolism activated in the TME and that the block of TLR7 and TLR8 signals drives a NK cell-dependent immune response against tumor cells (75). Based on the preliminary results achieved by agonist of TLR9 in metastatic melanoma, a phase-3 study (IMO-2125) is ongoing while the experimental arm is exploring the effect of Tilsotolimod in combination with ipilimumab in restoring the immunostimulatory activity, the DC activation, the $\mathrm{CD}^{+}$cell proliferation as well as a potential abscopal effect (81).

\section{Tumor Microenvironment and Immune Metabolism}

During the metastatic phase, melanoma cells orchestrate the establishment of an immune suppressive TME, by stimulating neo-angiogenesis, escaping from $\mathrm{T}$-cell recognition and developing resistance to radio/chemotherapy (82). The acquisition of these properties involves extracellular matrix remodeling, cytokine over-production, the recruitment of inhibitory cells and the intrinsic genetic mutations harbored by melanoma cells. Because an efficient immune response depends on the availability of nutrients and bioenergetics $(83,84)$, the high metabolic demand of the proliferating tumor cells and the formation of a stromal network overexposes T-cells to suppressive metabolites, which results in T-cell exhaustion and a reduction in the efficiency of their effector function (85). This metabolic reprogramming that involves immune cells during their activation has been recently defined as immunometabolism (85). In this context, the adenosine signaling that involves the CD39/C73 ectonucleotidases is a critical pathway used by melanoma cells to generate an immunosuppressive milieu (86). Indeed, the extracellular adenosine is the result of CD39 enzyme activation that induces the dephosphorylation of the adenosine triphosphate (ATP) to adenosine disphosphate (ADP) and then to adenosine monophosphate (AMP). Lastly, CD73 catalyzes the hydrolysis of AMP into phosphate and adenosine that suppresses the TME, thus establishing a "purinergic milieu." On the other hand, the CD39/CD73/adenosine signaling establishes an immunosuppressive melanoma microenvironment restraining both innate and adaptive anti-tumor immunity through dedicated adenosine receptors, namely $\mathrm{A} 1, \mathrm{~A} 2 \mathrm{~A}, \mathrm{~A} 2 \mathrm{~B}$, and $\mathrm{A} 3$ (87). These effects are variably modulated by the adenosine receptors while the $\mathrm{A} 2 \mathrm{~A}$ is the most common that outlines inhibitory signals by decreasing the activity of T-cells, NKs, NK-T cells, macrophages, and DCs as well as enhancing the recruitment of Treg and MDSCs in the TME (88). Moreover, studies completed in murine melanoma suggest that the A2B receptor promotes the $\mathrm{CD} 11 \mathrm{~b} / \mathrm{Gr} 1^{+}$MDSCs accumulation in tissues and lymph nodes nearby melanoma cells (89). With regard of DC function, adenosine has been described as a critical modulator of their activity during the early cross-priming presentation process as well as IL-10 production and inhibition of CXCL10 release.

The concomitant IL-10 production from DCs associated with low levels of IL-12 within the TME provokes the 
recruitment of Treg. Similarly, adenosine also inhibits the IL12 and IL-6 cytokine production by pDCs, thus interfering with immune response in viral infections, autoimmunity and cancer (90). Moreover, adenosine induces a defective maturation and differentiation of DCs toward a pro-angiogenic and tolerogenic phenotype, thus allowing tumor cells to escape the immune surveillance. In conclusion, adenosine produced by DCs suppresses the cross-priming presentation thus prompting the T-cell anergy while the adenosine released in TME inhibits the maturation and differentiation of DCs.

In addition, nicotinamide adenine dinucleotide (NAD) pathway also concurs to the immunometabolism dysfunction. $\mathrm{NAD}$ is a co-enzyme that controls the redox reactions in several metabolic pathways, including glycolysis through the nicotinamide phosphor-ribosyltransferase (NAMPT), a ratelimiting enzyme for the NAD synthesis frequently overexpressed in cancer cells (91). Moreover, NAMPT-specific inhibitors may deplete the NAD levels and restrain the cancer cell proliferation by inhibition of the energy production (92).

Another emerging inhibitory enzyme involved in the immunometabolism pathway is IDO, which is expressed by both melanoma cells and DCs, and mediates the conversion of tryptophan into kynurenines, thus inducing the local depletion of essential amino acids and restraining the recruitment of $\mathrm{CD} 8^{+}$ T-cells in favor of both Treg and MDSCs. Both cell types produce inhibitory cytokines as well as arginase-1, nitric oxide synthase, and reactive oxygen species (93). In CM patients, Treg levels were shown to correlate with clinical activity, thus demonstrating the utility of immune cell detection in the monitoring of melanoma progression, while MDSCs promote the differentiation of $\mathrm{CD}^{+}$ T-cells into $\mathrm{CD} 4^{+} / \mathrm{CD} 25^{+} / \mathrm{Foxp}^{+}$cells, which express TGF- $\beta$ and IL-10 as well as CTLA- 4 and PD-1. The binding of these latter receptors to ligands expressed on DCs limits the crosstalk with $\mathrm{CD}^{+} \mathrm{T}$-cells. Consequently, the peripheral and intra-tumoral expansion of $\mathrm{CD}^{+} / \mathrm{CD} 25^{+} / \mathrm{Foxp}^{+}$cells correlates directly with melanoma progression.

\section{Characteristics of the Immune Infiltrate}

Detailed knowledge of many aspects of the immune system together with the results achieved by immunotherapy has provided insights into the features of the T-cells that infiltrate the TME. The recruitment of immune cells is mostly regulated by the selectins, adhesion molecules and integrins expressed on melanoma cells and by the expression of CXCR3 chemokine receptor on T-cells and its ligands CXCL9, CXCL10, and CXCL11, which are key immune chemoattractants during interferon-induced inflammatory response (94). Based on the characteristics of the immune infiltrate, the cancer microenvironment may assume one of three phenotypes (Figure 1): the immune desert, the immune-excluded, and the inflamed phenotype. Their cellular and molecular properties are pivotal determinants of both melanoma progression and also therapeutic response (57).

The immune desert phenotype is the consequence of immunological ignorance, based on both the activation of tolerance and inappropriate priming. The anti-melanoma response to tumor-associated antigens and neo-antigen formation is therefore limited and antigen presentation inadequate. Other features of the immune desert milieu reflect the absence of pre-existing anti-tumor immunity, evidenced by modest T-cell helper activity, an insufficient number of T-cells and the recruitment to lymph nodes of immature and poorly co-stimulated DCs (95). In the immune-excluded phenotype, immune cells infiltrate the stroma surrounding the tumor cells but interact only minimally or not at all with the tumor itself. Thus, although the immune-excluded TME suggests a pre-existing anti-melanoma response, it seems to have been rendered ineffective by the inability of the immune cells to access the tumor (96). Based on similar observations in murine melanoma models, the primary role of $\mathrm{CD}_{103^{+}}$DCs seems to be the regulation of T-cell entry into the tumor mass (97). Both the immune desert and the immune-excluded phenotypes represent a non-inflamed TME. In the inflamed TME, the stromal tissue surrounding the melanoma cells is enriched in $\mathrm{CD} 4^{+}$and $\mathrm{CD} 8^{+}$ cells but they are hyper-exhausted. In addition, accessory cells such as monocytes, myeloid cells and Tregs are frequently detected. The tumor cells produce large amounts of IDO and activating cytokines, such as IFNs, IL-12, and IL-23, while overexpressing PD-L1-driven inhibitory signals, down-regulating MHC class I molecules and activating alternative pathways that weaken anti-cancer immunity (97). Thus, the inflamed profile suggests a pre-existing anti-tumor response that is arrested by immune suppression in the tumor bed. However, these cancers are also highly responsive to anti-PD-1 immunotherapy.

\section{THE ROLE OF INHIBITORY IMMUNE CHECKPOINTS IN DC-MEDIATED ANTI-CANCER IMMUNITY}

In melanoma, DCs provide the immune bridge linking innate and adaptive anti-tumor immunity (12). The DC maturation involves several well-studied co-stimulatory molecules. Besides, co-inhibitory receptors, most of which remain undefined, also mediate the DC maturation and function. Interestingly, the interplay of inhibitory signals in DC crosstalk with both tumor cells and activating or regulatory immune cells, modulates the effectiveness of DC-mediated anti-cancer immunity, thus shaping the TME (Table 1).

T-cell activation is a key event in the adaptive immune response and thus in the generation of a cell-mediated antitumor effect. Early T-cell activation is regulated by activating and inhibitory receptors, including CD28 and CTLA4, whose interplay results in integrated intracellular transcriptional signals that balance T-cell activation and self-tolerance. Another important step is the appropriate activation of effector $\mathrm{CD}^{+}$and $\mathrm{CD}^{+}{ }^{+} \mathrm{T}$-cells, which requires the engagement of MHC molecules expressed by DCs with the TCR, followed by the generation of a first signal consisting of the TCR/CD3 complex (110). TCR binding to antigen-loaded $\mathrm{MHC}$ is followed by a secondary signal that is driven by the ligands CD80 (B7-1) and CD86 (B7-2). These molecules act as co-stimulators via CD28 (98), which is highly expressed upon activation with CD80, and binds the inhibitory protein CTLA4 (102) largely exposed by T-cells and 


\section{DENDRITIC CELL $\longleftrightarrow$ MELANOMA CELS $\longleftrightarrow$ CD8 $^{+}$T-CELS}
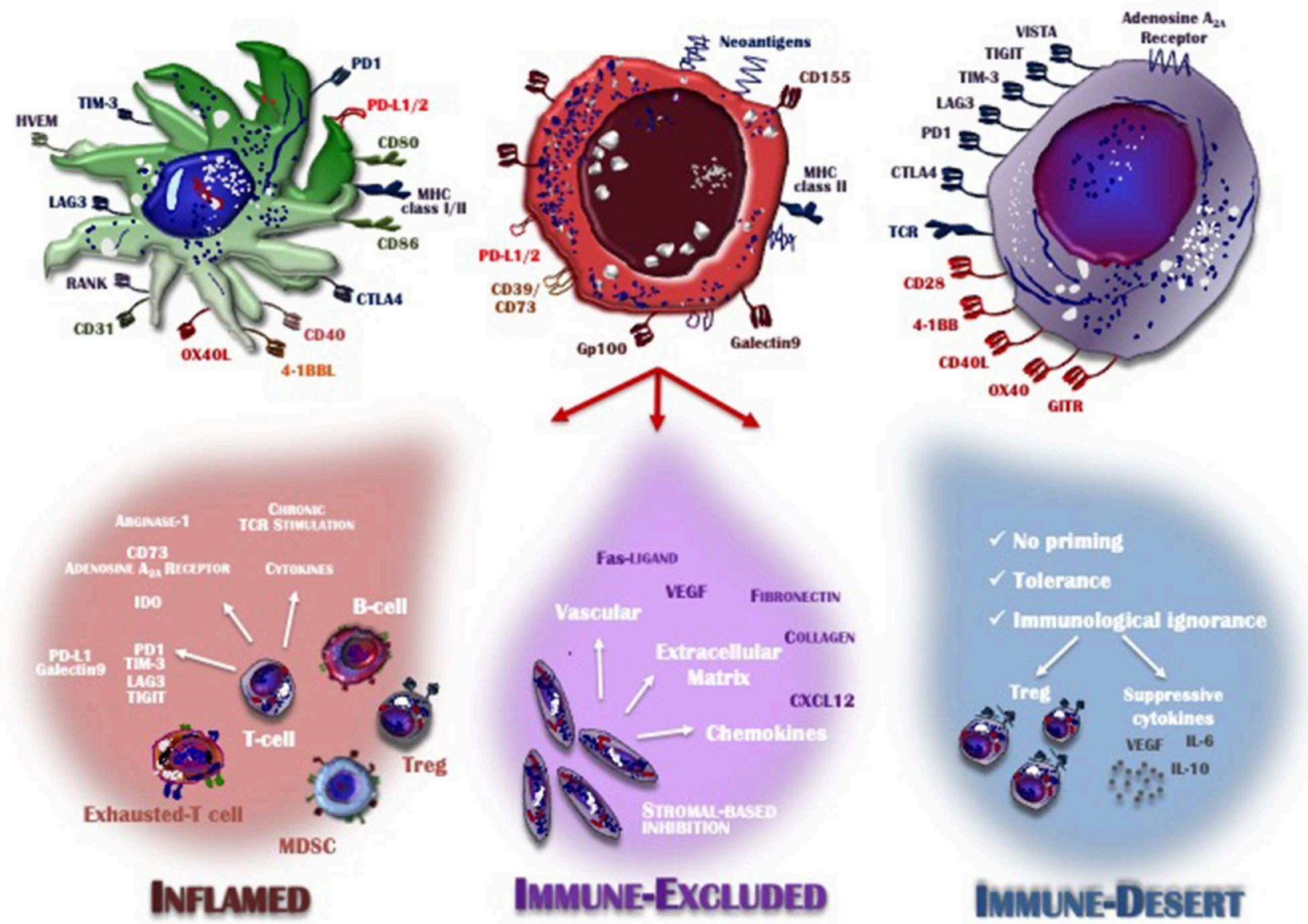

FIGURE 1 | Inflamed vs. non-inflamed tumor microenvironment. The melanoma microenvironment consists of a complex immune infiltrate consisting of dendritic cells (DCs), CD8 ${ }^{+}$T-cells, natural killer cells (NKs), regulatory T-cells (Treg), myeloid-derived suppressor cells (MDSCs), cytokines, enzymes, and negative modulators. Apart from melanoma cells characterized by the loss of HLA-I expression and thus already capable of evading the immune system control, the infiltrate assumes three different phenotypes: inflamed (red), immune-excluded (violet), and the immune desert (blue), depending on whether its features contribute to overcoming or supporting anti-tumor immunity control. Tumors with an immune-inflamed profile are highly responsive to immunotherapy but their rich immune infiltrate includes dysfunctional T-cells exhausted by chronic antigen exposure. Immune-excluded tumors are characterized by a pre-existing anti-melanoma response and specific stromal-based inhibition whereas immune-desert tumors are immunologically "ignorant," as T-cells rarely reach the tumor parenchyma or stroma. Melanoma cells, DCs and T-cells cross-talk through inhibitory or activating receptors, by which the immune response is induced or restrained, thus creating an equilibrium aimed at limiting melanoma cell proliferation and metastasis. MHC, major histocompatibility complex; CTLA-4, cytotoxic T-Lymphocyte antigen 4; PD-1, programmed death-1; PD-L1/2, programmed death-ligand 1/2; IDO, indoleamine 2,3-dioxygenase; TIM3, T-cell immunoglobulin mucin 3; LAG3, lymphocyte-activation gene 3; TIGIT, T cell Ig and ITIM domain; VISTA, V-domain Ig suppressor of T cell activation; TCR, T-cell receptor; MDSC, myeloid-derived suppressor cell; Treg, regulatory T cell; VEGF, vascular endothelial growth factor; IL, interleukin; CXCL, C-X-C motif ligand; GITR, glucocorticoid-induced TNFR-related protein; HVEM, herpes virus entry mediator; RANK, receptor activator of nuclear factor kappa-B.

especially Tregs. CTLA4 shows homology with CD28 (42, 100) and its expression by mature DCs $(104,111)$ inhibits their own maturation through the autocrine uptake of CTLA4-enriched vesicles (112).

A relevant breakthrough in melanoma has been obtained by immunotherapy combinations, revealing that the CTLA4 activation mostly occurs in lymph nodes while the modulation of T-cell functions by PD-1 stimulation has been mostly described in the microenvironment of peripheral tissues (113). The PD-1 engagement by related ligands, PD-L1 (B7-H1) and
PD-L2 (B7-DC) that are differently expressed by tumor and immune cells, is known to recruit phosphatase SHP-1 and SHP-s to specific ITIM (immune-receptor tyrosine-based inhibitory motif) and ITSM (immune receptor tyrosine-based switch motif) cytosolic loci, thus inducing the de-phosphorylation of proximal TCR signaling that concurs to suppress both mTOR and PI3K/AKT intracellular pathways. In contrast to the restricted levels of PD-L2 on activated macrophages, PD-L1 is predominantly expressed on non-hematopoietic and immune cells. PD-L1 is constitutively present on B cells, macrophages, 
TABLE 1 | Key molecules and receptors implicated in the DC/melanoma interplay.

\begin{tabular}{|c|c|c|}
\hline Receptor(s)/ligand(s) & Effect(s) on lymph nodes/TME & References \\
\hline MHC-class $1 / I I$ & $\begin{array}{l}\text { Initiation of the antigen-specific immune response, antigen processing and presentation, } \\
\text { and the cross-priming processes }\end{array}$ & $(17)$ \\
\hline B7-1 (CD80)/B7-2 (CD86) & $\begin{array}{l}\text { Modulation of DCs co-stimulation and cross-priming interference } \\
\text { based on activating/inhibitory receptor expression }\end{array}$ & (98) \\
\hline $\begin{array}{l}\text { OX40 (CD134) } \\
\text { OX40L (CD252) }\end{array}$ & Induction of maturation, activation, and survival of DCs & (99) \\
\hline $\begin{array}{l}\text { CD40 (CD154) } \\
\text { CD40L }\end{array}$ & Co-stimulatory molecule that play a central role in B and T-cell activation & $(75)$ \\
\hline CD28 & $\begin{array}{l}\text { "Secondary signal:" co-stimulation of DCs inducing the complete activation } \\
\text { and effector functions in T-cells }\end{array}$ & $(100)$ \\
\hline $\begin{array}{l}\text { 4-1BB (CD137) } \\
4-1 B B L\end{array}$ & CD137 ligand signaling induces human monocyte to dendritic cell differentiation & $(101)$ \\
\hline CTLA4 (CD152) & $\begin{array}{l}\text { CTLA4 exerts an inhibitory role in mature DCs through the autocrine uptake of vesicles } \\
\text { enriched of CTLA4 molecules that restrain the co-stimulation }\end{array}$ & $(102)$ \\
\hline PD1 & Suppression of CD8 ${ }^{+}$T-cell activity and decrease of T-cell infiltration & $(103)$ \\
\hline PD-L1 (CD274)/PD-L2 & Inhibition of CD4+ and CD8 ${ }^{+}$T-cell activity; promotion of Tregs expansion; abrogation of NKs function. & $(104)$ \\
\hline TIM-3 & Induction of apoptosis of Th1 polarized T-cells & $(105)$ \\
\hline LAG3 & $\begin{array}{l}\text { LAG-3 is constitutively expressed on pDCs, playing an important role in both the homeostatic } \\
\text { maintenance and activation-induced expansion of pDCs }\end{array}$ & $(106)$ \\
\hline BTLA/HVEM & Induction of Treg differentiation, up-regulating the expression of CD5 by T-cells & $(107)$ \\
\hline CD31 (PECAM-1) & Upholding CD31 signaling during maturation converts stimulated DCs in TME into tolerogenic cells & $(108)$ \\
\hline RANK & Induction of maturation, activation and survival of DCs & $(109)$ \\
\hline
\end{tabular}

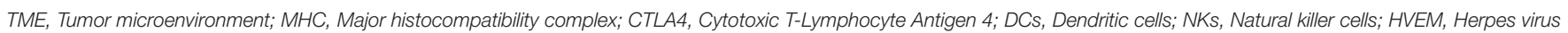
entry mediator; pDCs, Plasmacytoid dendritic cells; RANK, Receptor activator of nuclear factor kappa-B.

T-cells and DCs and is upregulated after the stimulation of pro-inflammatory cytokines such as IFN. Moreover, it has been also described a "constitutive" oncogenic signaling able to over-expresses PD-L1 ligand on tumor cells, regardless of inflammatory signals in the TME (101). This supports the notion that PD-L1 acts as molecular cloak on both host immune and tumor cells to protect cancer from cytolysis by T-cells.

Therefore, the PD-1 interaction with both PD-L1 and PD-L2 promotes the T-cell dysfunction, exhaustion, and anergy (101). Apart from the interaction between $\mathrm{T}$ lymphocytes and tumor cells, the engagement of the PD-1/PD-L1 axis also occurs among immune cell types infiltrating the TME. To this regard, DCmediated anti-tumor immunity driven by the PD-1/PD-L1 axis involves different mechanisms, as the cells express either the receptor or the ligands that interact with $\mathrm{PD}-1^{+} / \mathrm{PD}-\mathrm{L} 1^{+} / 2^{+}$ cells. PD-1 expression by $\mathrm{mDCs}$ and $\mathrm{pDCs}$ is up-regulated by pro-inflammatory cytokines that have accumulated in the TME $(114,115)$ while PD-L1 ${ }^{+}$DCs expand the $\mathrm{CD}^{+} / \mathrm{CD} 25^{+} / \mathrm{FoxP}^{+}$ Treg population, leading to immune suppression (116). The role of the PD1/PD-L1 axis in cross-talk between DCs and other innate immune cells, including NKs, NK-T cells, $\gamma \delta \mathrm{T}-$ cells, regulatory MDSCs and TAMs, is still unknown. However, inhibition of the PD-1/PD-L1 axis was shown to reinforce the NK activity in multiple myeloma $(105,107,117)$, and in a pre-clinical melanoma model, the up-regulation of $\mathrm{PD}$ L1 by tumor-infiltrating and tumor-draining lymph nodes resulted in decreased PD-1 ${ }^{+}$DC cross-priming activity (118). In addition to CTLA4 and PD-1 inhibitory receptors, other emerging immune checkpoint molecules (Figure 1) involved in DC-mediated immunity include TIM-3 (T cell immunoglobulin and mucin domain-3), BTLA, LAG3, and CD31 (119, 120). The role of $\mathrm{TIM}-3^{+}$T-cells in the modulation of the TME has been largely investigated in parallel with the membrane expression of this receptor by tumor-associated DCs (108). TIM3 $^{+}$DCs promote the apoptosis of Th1 T-cells subsequent to receptor interaction with the galectin-9 ligand (121). In a mouse model of fibrosarcoma, the dual inhibition of TIM-3 and PD-1 or CTLA4 reduced tumor growth (122). BTLA is an immunoglobulin domain superfamily protein that controls the expression of CD5 by T-cells via engagement of the ligand HVEM (herpes virus entry mediator), which results in MEK phosphorylation and, in turn, Treg differentiation and peripheral tolerance (109). CD31 forms a co-receptor with PECAM-1 that is constitutively expressed by resting DCs $(123,124)$. Recent studies have demonstrated that CD31/PECAM-1 engagement by $\mathrm{T}$ cells balances their activation and tolerance whereas co-receptor inhibition favors the maturation and migration of resident DCs to draining lymph nodes (125).

Although the RANK-L/RANK axis represents a key regulator of the bone remodeling and critical for the osteoclastogenesis machinery, RANK-L also drives the DC differentiation and survival $(126,127)$. Indeed, the reciprocal interaction between T-cells and DCs through RANKL/RANK system induces both NF-kB activation and pro-inflammatory cytokines release, thus providing the DC survival and viability (128). By contrast, an immune suppressive alternative activity of the RANKL/RANK 
axis in TME has been described because RANKL induces activation of RANK on melanoma-associated DCs thus exerting a tolerogenic effect (129).

\section{DENDRITIC CELLS AND PERSONALIZED THERAPY IN MELANOMA}

Besides immune checkpoint receptor expression by DCs, the mechanisms that contribute to inhibiting the tumor milieu include metabolic reprogramming, such as induced by the extracellular release of adenosine. In fact, recent data have demonstrated that $\mathrm{A} 2 \mathrm{~A}$ adenosine receptor blockade by a selective antagonist or CD73 inhibitor reinforces the efficacy of DC-based vaccination (130). The therapeutic potential of DC vaccination may likewise be strengthened by a blockade of the pioneering CD28/CTLA4 and PD1/PD-L1 pathways. Other studies have shown that the efficacy of vaccination is highly likely in tumors bearing a low tumor mutational burden, whereas a therapy based on the blockade of immune checkpoints may have greater success in patients with immunogenic melanoma characterized by a high TMB $(47,131)$.

However, checkpoint inhibitors poorly stimulate the immune response in patients with tumors surrounded by a limited Tcell infiltrate (132). The DCs that co-localize in the peri-tumoral infiltrate consist of two specialized subsets: $\mathrm{CD} 103^{+} / \mathrm{CD}^{+}$ DCs, characterized by excellent priming and cross-presentation activity, and $\mathrm{CD} 11 \mathrm{~b}^{+} \mathrm{DCs}$, which promote the activity of $\mathrm{CD}^{+}$ T-helper cells (96). Nonetheless, molecular investigations in human metastatic melanoma specimens revealed a correlation between the activation of the $\mathrm{Wnt} / \beta$-catenin signaling and resistance to anti-PD- 1 and anti-CTLA- 4 monoclonal antibodies

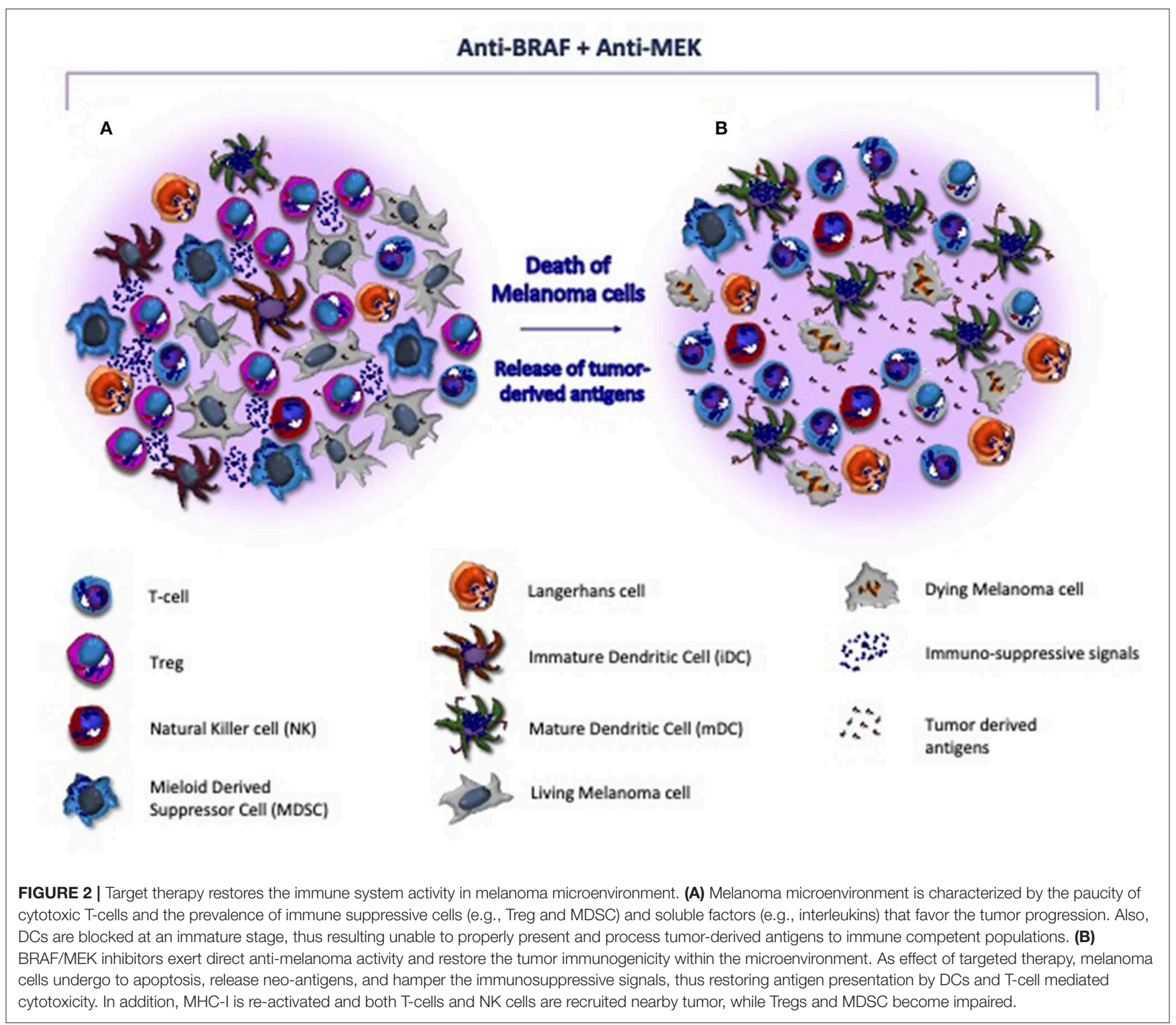


(133). Moreover, defective activation of CCL4 chemokine was shown to result in the reduced recruitment of $\mathrm{CD}_{103}{ }^{+}$DCs. The populations of immune cells infiltrating the tumor bed in melanoma and delivering intact antigens to tumor-draining lymph nodes have been extensively studied in murine models of melanoma and in humans (134).

Other promising therapeutic strategies in metastatic CM include BRAF/MEK inhibitors with the potential to restore immune system properties by increasing the recruitment of $\mathrm{CD}^{+}$T-cells (Figure 2), their infiltration of the tumor and the release of tumor antigens avidly recognized by cytotoxic cells (135). Also, the innate immunity system may be, however, affected by BRAF/MEK inhibitors. In this context, the blockade of MAPK signaling was shown to inhibit the negative effect exerted by melanoma cells in terms of DC differentiation, cytokine production, antigen cross-priming and capture, thus renewing the functions of these cells $(136,137)$. A number of reports demonstrated that the blockade of MAPK pathway restores the anti-melanoma immunity by up-regulating the costimulation in terms of CD83, CD80, and CD86 expression by DCs (136). Also, NKs are influenced by BRAF/MEK inhibitors that induce the ERK1/2 phosphorylation, the upregulation of CD69, the IFN- $\gamma$ secretion thus restoring their cytotoxic activity (138). Furthermore, other immune modulatory effects induced by these therapies include the impairment of MDSCs and Tregs activity, the reduced production of IL-10, IL-6, and VEGF by melanoma cells in TME as well as the down-modulation of the $\mathrm{C}-\mathrm{C}$ chemokine ligand (CCL)-2 that is mostly involved in macrophage recruitment and survival $(106,139,140)$.

\section{CONCLUSIONS AND FUTURE PERSPECTIVES}

The biology of melanoma cells is closely associated with immune system regulation. As matter of fact, the relevance of DCs has been largely accepted as a needful immune population that connects innate and adaptive immune system, although their

\section{REFERENCES}

1. Siegel RL, Miller KD, Jemal A. Cancer statistics, 2017. CA Cancer J Clin. (2017) 67:7-30. doi: 10.3322/caac.21387

2. Mannavola F, Tucci M, Felici C, Stucci S, Silvestris F. miRNAs in melanoma: a defined role in tumor progression and metastasis. Expert Rev Clin Immunol. (2015) 12:79-89. doi: 10.1586/1744666X.2016.1100965

3. Karachaliou N, Pilotto S, Teixidó C, Viteri S, González-Cao M, Riso A, et al. Melanoma: oncogenic drivers and the immune system. Ann Transl Med. (2015) 3:265. doi: 10.3978/j.issn.2305-5839.2015.08.06

4. Bhatia A, Kumar Y. Cancer-immune equilibrium: questions unanswered. Cancer Microenviron. (2011) 4:209-17. doi: 10.1007/s12307-011-0065-8

5. Han D, Zager JS, Shyr Y, Chen H, Berry LD, Iyengar S, et al. Clinicopathologic predictors of sentinel lymph node metastasis in thin melanoma. J Clin Oncol. (2013) 31:4387-93. doi: 10.1200/JCO.2013.50.1114

6. Fridman WH, Pagès F, Sautès-Fridman C, Galon J. The immune contexture in human tumours: impact on clinical outcome. Nat Rev Cancer. (2012) 12:298-306. doi: 10.1038/nrc3245 definite role requires further knowledge. Interestingly, the DC modulation in the melanoma microenvironment shapes both tumor development and anti-melanoma immunity. Therefore, DCs result as an attractive target for the manipulation of the immune system for therapeutic purposes aimed to enhance the immune response or alternatively to overcome the onset of acquired resistance to cancer immunotherapy. However, the complexity of the DCs system requires a thoughtful and rational manipulation of DCs to obtain protective or therapeutic immunity.

Moreover, why other immune cells infiltrating the tumor bed may either promote or block melanoma progression remains unclear, as does the discrepancy between the quality of the immune infiltrate and the clinical outcome in the majority of CM patients (141). Consequently, to achieve the better management of patients, the focus has shifted to the immune component of the TME. A recently developed immunoscore used in melanoma (142) and in colon cancer (143) has demonstrated that, in the TME, not only the functional features of T-cells but also their spatial distribution, density and expression of PD-L1 are crucial determinants of the response to immunotherapy. In addition, an index based on multiparametric analyses has been created to better define the spatial relationship at the invasive margin of the tumor and its stromal components. Further efforts at understanding the complex machinery that underlies the interplay between immune cells and melanoma are needed to design effective immunotherapies and to identify biomarkers that predict tumor responsiveness.

\section{AUTHOR CONTRIBUTIONS}

All authors listed have made a substantial, direct and intellectual contribution to the work, and approved it for publication.

\section{FUNDING}

This work was funded by a grant (\# IG17536) from the AIRC (Italian Association for Cancer Research).

7. Castaneda CA, Castillo M, Torres-Cabala C, Bernabe LA, Casavilca $\mathrm{S}$, Villegas V, et al. Relationship between tumor-associated immune infiltrate and p16 staining over clinicopathological features in acral lentiginous melanoma. Clin Transl Oncol. (2019) 21:1127-34. doi: 10.1007/s12094-019-02033-x

8. Madonna G, Ballesteros-Merino C, Feng Z, Bifulco C, Capone M, Giannarelli $\mathrm{D}$, et al. PD-L1 expression with immune-infiltrate evaluation and outcome prediction in melanoma patients treated with ipilimumab. Oncoimmunology. (2018) 7:e1405206. doi: 10.1080/2162402X.2017.1405206

9. Kitano S, Nakayama T, Yamashita M. Biomarkers for immune checkpoint inhibitors in melanoma. Front Oncol. (2018) 8:270. doi: 10.3389/fonc. 2018.00270

10. Dunn GP, Old LJ, Schreiber RD. The immunobiology of cancer immunosurveillance and immunoediting. Immunity. (2004) 21:137-48. doi: 10.1016/j.immuni.2004.07.017

11. Passarelli A, Mannavola F, Stucci LS, Tucci M, Silvestris F. Immune system and melanoma biology: a balance between immunosurveillance and immune escape. Oncotarget. (2017) 8:106132-42. doi: 10.18632/oncotarget.22190 
12. Mittal D, Gubin MM, Schreiber RD, Smyth MJ. New insights into cancer immunoediting and its three component phases-elimination, equilibrium and escape. Curr Opin Immunol. (2014) 27:16-25. doi: 10.1016/j.coi.2014. 01.004

13. Whiteside TL. The tumor microenvironment and its role in promoting tumor growth. Oncogene. (2008) 27:5904-12. doi: 10.1038/onc.2008.271

14. Bontkes HJ, De Gruijl TD, Schuurhuis GJ, Scheper RJ, Meijer CJLM, Hooijberg E. Expansion of dendritic cell precursors from human CD34 ${ }^{+}$ progenitor cells isolated from healthy donor blood; growth factor combination determines proliferation rate and functional outcome. J Leukoc Biol. (2002) 72:321-9. doi: 10.1189/jlb.72.2.321

15. Tucci M, Stucci S, Strippoli S, Dammacco F, Silvestris F. Dendritic cells and malignant plasma cells: an alliance in multiple myeloma tumor progression? Oncologist. (2011) 16:1040-8. doi: 10.1634/theoncologist.2010-0327

16. Tucci M, Stucci S, Passarelli A, D’Oronzo S, Silvestris F. Everolimus restrains the IL-17A-dependent osteoclast-like transdifferentiation of dendritic cells in multiple myeloma. Exp Hematol. (2016) 47:48-53. doi: 10.1016/j.exphem.2016.10.004

17. Banchereau J, Steinman RM. Dendritic cells and the control of immunity. Nature. (1998) 392:245-52. doi: 10.1038/32588

18. Tucci M, Stucci S, Passarelli A, Giudice G, Dammacco F, Silvestris F. The immune escape in melanoma: role of the impaired dendritic cell function. Expert Rev Clin Immunol. (2014) 10:1395-404. doi: 10.1586/1744666X.2014.955851

19. Ghirelli C, Reyal F, Jeanmougin M, Zollinger R, Sirven P, Michea P, et al. Breast cancer cell-derived GM-CSF licenses regulatory Th2 induction by plasmacytoid predendritic cells in aggressive disease subtypes. Cancer Res. (2015) 75:2775-87. doi: 10.1158/0008-5472.CAN-14-2386

20. Di Domizio J, Demaria O, Gilliet M. Plasmacytoid dendritic cells in melanoma: can we revert bad into good? J Invest Dermatol. (2014) 134:1797800. doi: 10.1038/jid.2014.155

21. Collin M, Bigley V. Human dendritic cell subsets: an update. Immunology. (2018) 154:3-20. doi: 10.1111/imm.12888

22. Tucci M, Stucci LS, Mannavola F, Passarelli A, D’Oronzo S, Lospalluti L, et al. Defective levels of both circulating dendritic cells and T-regulatory cells correlate with risk of recurrence in cutaneous melanoma. Clin Transl Oncol. (2018) 21:845-54. doi: 10.1007/s12094-018-1993-2

23. Beavis PA, Stagg J, Darcy PK, Smyth MJ. CD73: a potent suppressor of antitumor immune responses. Trends Immunol. (2012) 33:231-7. doi: 10.1016/j.it.2012.02.009

24. O'Keeffe M, Mok WH, Radford KJ. Human dendritic cell subsets and function in health and disease. Cell Mol Life Sci. (2015) 72:4309-25. doi: 10.1007/s00018-015-2005-0

25. Guilliams M, Ginhoux F, Jakubzick C, Naik SH, Onai N, Schraml BU, et al. Dendritic cells, monocytes and macrophages: a unified nomenclature based on ontogeny. Nat Rev Immunol. (2014) 14:571-8. doi: 10.1038/nri3712

26. Granot T, Senda T, Carpenter DJ, Matsuoka N, Weiner J, Gordon CL, et al. Dendritic cells display subset and tissue-specific maturation dynamics over human life. J Control Release. (2017) 46:504-15. doi: 10.1016/j.immuni.2017.02.019

27. MacDonald KPA, Munster DJ, Clark GJ, Dzionek A, Schmitz J, Hart DNJ. Characterization of human blood dendritic cell subsets. Blood. (2002) 100:4512-20. doi: 10.1182/blood-2001-11-0097

28. Swiecki M, Colonna M. The multifaceted biology of plasmacytoid dendritic cells. Nat Rev Immunol. (2015) 15:471-85. doi: 10.1038/nri3865

29. Carpentier S, Manh T-PV, Chelbi R, Henri S, Malissen B, Haniffa M, et al. Comparative genomics analysis of mononuclear phagocyte subsets confirms homology between lymphoid tissue-resident and dermal XCR1(+) DCs in mouse and human and distinguishes them from Langerhans cells. J Immunol Methods. (2016) 432:35-49. doi: 10.1016/j.jim.2016.02.023

30. Nizzoli G, Krietsch J, Weick A, Steinfelder S, Facciotti F, Gruarin P, et al. Human CD1c+ dendritic cells secrete high levels of IL-12 and potently prime cytotoxic T-cell responses. Blood. (2013) 122:932-42. doi: 10.1182/blood-2013-04-495424

31. De Monte A, Olivieri C-V, Vitale S, Bailleux S, Castillo L, Giordanengo $\mathrm{V}$, et al. CD1c-Related DCs that express CD207/langerin, but are distinguishable from langerhans cells, are consistently present in human tonsils. Front Immunol. (2016) 7:197. doi: 10.3389/fimmu.2016.00197
32. Hieronymus T, Zenke M, Baek J-H, Seré K. The clash of Langerhans cell homeostasis in skin: should I stay or should I go? J Control Release. (2014) 41:30-8. doi: 10.1016/j.semcdb.2014.02.009

33. Banchereau J, Thompson-Snipes L, Zurawski S, Blanck J-P, Cao Y, Clayton $\mathrm{S}$, et al. The differential production of cytokines by human Langerhans cells and dermal CD14 ${ }^{+}$DCs controls CTL priming. Blood. (2012) 119:5742-9. doi: 10.1182/blood-2011-08-371245

34. Barry KC, Hsu J, Broz ML, Cueto FJ, Binnewies M, Combes AJ, et al. A natural killer-dendritic cell axis defines checkpoint therapyresponsive tumor microenvironments. Nat Med. (2018) 24:1178-91. doi: 10.1038/s41591-018-0085-8

35. Spranger S, Dai D, Horton B, Gajewski TF. Tumor-residing Batf3 dendritic cells are required for effector $\mathrm{T}$ cell trafficking and adoptive $\mathrm{T}$ cell therapy. Cancer Cell. (2017) 31:711-23.e4. doi: 10.1016/j.ccell.2017.04.003

36. Ding Y, Wilkinson A, Idris A, Fancke B, O'Keeffe M, Khalil D, et al. FLT3ligand treatment of humanized mice results in the generation of large numbers of CD141+ and CD1c+ dendritic cells in vivo. J Immunol. (2014) 192:1982-9. doi: 10.4049/jimmunol.1302391

37. Böttcher JP, Bonavita E, Chakravarty P, Blees H, Cabeza-Cabrerizo M, Sammicheli S, et al. NK cells stimulate recruitment of $\mathrm{cDC} 1$ into the tumor microenvironment promoting cancer immune control. Cell. (2018) 172:1022-37.e14. doi: 10.1016/j.cell.2018.01.004

38. Spranger S, Luke JJ, Bao R, Zha Y, Hernandez KM, Li Y, et al. Density of immunogenic antigens does not explain the presence or absence of the T-cellinflamed tumor microenvironment in melanoma. Proc Natl Acad Sci USA. (2016) 113:E7759-68. doi: 10.1073/pnas.1609376113

39. Su Y, Jackson EK, Gorelik E. Receptor desensitization and blockade of the suppressive effects of prostaglandin $\mathrm{E}(2)$ and adenosine on the cytotoxic activity of human melanoma-infiltrating T lymphocytes. Cancer Immunol Immunother. (2010) 60:111-22. doi: 10.1007/s00262-010-0924-z

40. Burke S, Lakshmikanth T, Colucci F, Carbone E. New views on natural killer cell-based immunotherapy for melanoma treatment. Trends Immunol. (2010) 31:339-45. doi: 10.1016/j.it.2010.06.003

41. Eil R, Vodnala SK, Clever D, Klebanoff CA, Sukumar M, Pan JH, et al. Ionic immune suppression within the tumour microenvironment limits $\mathrm{T}$ cell effector function. Nature. (2016) 537:539-43. doi: 10.1038/nature19364

42. Curtsinger JM, Schmidt CS, Mondino A, Lins DC, Kedl RM, Jenkins MK, et al. Inflammatory cytokines provide a third signal for activation of naive CD4+ and CD8+ T cells. J Immunol. (1999) 162:3256-62.

43. Sansom DM. CD28, CTLA-4 and their ligands: who does what and to whom? Immunology. (2000) 101:169-77. doi: 10.1046/j.1365-2567.2000.00121.x

44. Schreiber RD, Old LJ, Smyth MJ. Cancer immunoediting: integrating immunity's roles in cancer suppression and promotion. Science. (2011) 331:1565-70. doi: 10.1126/science.1203486

45. Daley D, Zambirinis CP, Seifert L, Akkad N, Mohan N, Werba G, et al. $\gamma \delta \mathrm{T}$ cells support pancreatic oncogenesis by restraining $\alpha \beta \mathrm{T}$ cell activation. Cell. (2016) 166:1485-99.e15. doi: 10.1016/j.cell.2016.07.046

46. Karin M. Nuclear factor-kappaB in cancer development and progression. Nature. (2006) 441:431-6. doi: 10.1038/nature04870

47. Wesch D, Peters C, Siegers GM. Human gamma delta T regulatory cells in cancer: fact or fiction? Front Immunol. (2014) 5:598. doi: 10.3389/fimmu.2014.00598

48. Lawrence MS, Stojanov P, Polak P, Kryukov GV, Cibulskis K, Sivachenko A, et al. Mutational heterogeneity in cancer and the search for new cancerassociated genes. Nature. (2013) 499:214-8. doi: 10.1038/nature12213

49. Alexandrov LB, Nik-Zainal S, Wedge DC, Aparicio SAJR, Behjati S, Biankin AV, et al. Signatures of mutational processes in human cancer. Nature. (2013) 500:415-21. doi: 10.1038/nature12477

50. Aris M, Barrio MM, Mordoh J. Lessons from cancer immunoediting in cutaneous melanoma. Clin Dev Immunol. (2012) 2012:192719. doi: $10.1155 / 2012 / 192719$

51. Yamaguchi K, Mishima K, Ohmura H, Hanamura F, Ito M, Nakano M, et al. Activation of central/effector memory $\mathrm{T}$ cells and T-helper 1 polarization in malignant melanoma patients treated with anti-programmed death-1 antibody. Cancer Sci. (2018) 109:3032-42. doi: 10.1111/cas.13758

52. Redondo P, Sánchez-Carpintero I, Bauzá A, Idoate M, Solano T, Mihm MC. Immunologic escape and angiogenesis in human malignant melanoma. J Am Acad Dermatol. (2003) 49:255-63. doi: 10.1067/S0190-9622(03)00921-6 
53. Chen DS, Mellman I. Oncology meets immunology: the cancer-immunity cycle. Immunity. (2013) 39:1-10. doi: 10.1016/j.immuni.2013.07.012

54. Swartz MA, Lida N, Roberts EW, Sangaletti S, Wong MH, Yull FE, et al. Tumor microenvironment complexity: emerging role in cancer therapy. Cancer Res. (2012) 72: 2473-80. doi: 10.1158/0008-5472.CAN-12-0122

55. Liu B, Qu L, Yan S. Cyclooxygenase-2 prmotes tumor growth and suppresses tumor immunity. Cancer Cell Int. (2015) 15:106. doi: 10.1186/s12935-015-0260-7

56. Wang D, Dubois RN. The role of prostaglandin-E2 in tumorassociated immunosuppression. Trends Mol Med. (2016) 22:1-3. doi: 10.1016/j.molmed.2015.11.003

57. Chen DS, Mellman I. Elements of cancer immunity and the cancer-immune set point. Nature. (2017) 541:321-30. doi: 10.1038/nature21349

58. Tripathi SC, Peters HL, Taguchi A, Katayama H, Wang H, Momin A, et al. Immunoproteasome deficiency is a feature of non-small cell lung cancer with a mesenchymal phenotype as is associated with poor outcome. Proc Natl Acad Sci USA. (2016) 113:E1555-64. doi: 10.1073/pnas.1521812113

59. Van Hateren A, James E, Bailey A, Phillips A, Dalchau N, Elliott T. The cell biology of major histocompatibility complex class I assembly: towards a molecular understanding. Tissue Antigens. (2010) 76:259-75. doi: 10.1111/j.1399-0039.2010.01550.x

60. Goeppert B, Frauenschuh L, Zucknick M, Roessler S, Mehrabi A, Hafezi M, et al. Major histocompatibility complex class I expression impacts on patient survival and type and density of immune cells in biliary tract cancer. $\mathrm{Br} J$ Cancer. (2015) 113:1343-9. doi: 10.1038/bjc.2015.337

61. Rooney MS, Shukla SA, Wu CJ, Getz G, Hacohen N. Molecular and genetic properites of tumors associated with local immune cytolitic activity. Cell. (2015) 160:48-61. doi: 10.1016/j.cell.2014.12.033

62. Reeves E, James E. Antigen processing and immune regulation in the response to tumors. Immunology. (2016) 150:16-24. doi: 10.1111/imm.12675

63. Zhang S, Kohli K, Black RG, Yao L, Spadinger SM, He Q, et al. Systemic interferon- $\gamma$ increases MHC class-I expression and T-cell infiltration in cold tumors: results of a phase 0 clinical trial. Cancer Immunol Res. (2019) 7:1237-43. doi: 10.1158/2326-6066.CIR-18-0940

64. Tucci M, Mannavola F, Passarelli A, Stucci LS, Cives M, Silvestris F. Exosomes in melanoma: a role in tumor progression, metastasis and impaired immune system activity. Oncotarget. (2018) 9:20826-37. doi: 10.18632 /oncotarget. 24846

65. van Willigen WW, Bloemendal M, Gerritsen WR, Schreibelt G, de Vries IJM, Bol KF. Dendritic cell cancer therapy: vaccinating the right patient at the right time. Front Immunol. (2018) 9:2265. doi: 10.3389/fimmu.2018.02265

66. Weber M, Hauschild R, Schwarz J, Moussion C, de Vries I, Legler DF, et al. Interstitial dendritic cell guidance by haptotactic chemokine gradients. Science. (2013) 339:328-32. doi: 10.1126/science.1228456

67. Ulvmar MH, Werth K, Braun A, Kelay P, Hub E, Eller K, et al. The atypical chemokine receptor CCRL1 shapes functional CCL21 gradients in lymph nodes. Nat Immunol. (2014) 15:623-30. doi: 10.1038/ni.2889

68. Krappmann D, Wegener E, Sunami Y, Esen M, Thiel A, Mordmuller B, et al. The I B kinase complex and NF- B act as master regulators of lipopolysaccharide-induced gene expression and control subordinate activation of AP-1. Mol Cell Biol. (2004) 24:6488-500. doi: 10.1128/MCB.24.14.6488-6500.2004

69. Ohl L, Mohaupt M, Czeloth N, Hintzen G, Kiafard Z, Zwirner J, et al. CCR7 governs skin dendritic cell migration under inflammatory and steadystate conditions. Immunity. (2004) 21:279-88. doi: 10.1016/j.immuni.2004. 06.014

70. Qu C, Edwards EW, Tacke F, Angeli V, Llodrá J, Sanchez-Schmitz G, et al. Role of CCR8 and other chemokine pathways in the migration of monocytederived dendritic cells to lymph nodes. J Exp Med. (2004) 200:1231-41. doi: $10.1084 /$ jem.20032152

71. Pflicke H, Sixt M. Preformed portals facilitate dendritic cell entry into afferent lymphatic vessels. J Exp Med. (2009) 206:2925-35. doi: 10.1084/jem.20091739

72. Tal O, Lim HY, Gurevich I, Milo I, Shipony Z, Ng LG, et al. DC mobilization from the skin requires docking to immobilized CCL21 on lymphatic endothelium and intralymphatic crawling. J Exp Med. (2011) 208:2141-53. doi: $10.1084 /$ jem.20102392
73. Tan S-Y, Roediger B, Weninger W. The role of chemokines in cutaneous immunosurveillance. Immunol Cell Biol. (2015) 93:337-46. doi: $10.1038 /$ icb.2015.16

74. Wang Y, Szretter KJ, Vermi W, Gilfillan S, Rossini C, Cella M, et al. IL34 is a tissue-restricted ligand of CSF1R required for the development of Langerhans cells and microglia. Nat Immunol. (2012) 13:753-60. doi: $10.1038 /$ ni.2360

75. Singh M, Vianden C, Cantwell MJ, Dai Z, Xiao Z, Sharma M, et al. Intratumoral CD40 activation and checkpoint blockade induces $\mathrm{T}$ cellmediated eradication of melanoma in the brain. Nat Commun. (2017) 8:1447. doi: 10.1038/s41467-017-01572-7

76. Gerlini G, Di Gennaro P, Mariotti G, Urso C, Chiarugi A, Caporale R, et al. Human Langerhans cells are immature in melanoma sentinel lymph nodes. Blood. (2012) 119:4807-8. doi: 10.1182/blood-2011-12-401067

77. Hemmi H, Akira S. TLR signalling and the function of dendritic cells. Chem Immunol Allergy. (2005) 86:120-35. doi: 10.1159/000086657

78. Tang M, Diao J, Gu H, Khatri I, Zhao J, Cattral MS. Toll-like receptor 2 activation promotes tumor dendritic cell dysfunction by regulating IL-6 and IL-10 receptor signaling. Mol Ther Nucleic Acids. (2015) 13:2851-64. doi: 10.1016/j.celrep.2015.11.053

79. Shime H, Maruyama A, Yoshida S, Takeda Y, Matsumoto M, Seya T. Toll-like receptor 2 ligand and interferon- $\gamma$ suppress anti-tumor $\mathrm{T}$ cell responses by enhancing the immunosuppressive activity of monocytic myeloid-derived suppressor cells. Oncoimmunology. (2017) 7:e1373231. doi: 10.1080/2162402X.2017.1373231

80. Smith M, García-Martínez E, Pitter MR, Fucikova J, Spisek R, Zitvogel $\mathrm{L}$, et al. Trial watch: toll-like receptor agonists in cancer immunotherapy. Oncoimmunology. (2018) 7:e1526250. doi: 10.1080/2162402X.2018.1526250

81. Butler MO, Robert C, Negrier S, Kim In G, Walker JWT, Kraisova I, et al. Illuminate 301: a randomized phase- 3 study of tilsotolimod in combination with ipilimumab compared to ipilimumab alone in patients with advanced melanoma following progression on or after anti-PD-1 therapy. J Clin Oncol. (2019) 37:TPS9599. doi: 10.1200/JCO.2019.37.15_suppl.TPS9599

82. Hanahan D, Coussens LM. Accessories to the crime: functions of cells recruited to the tumor microenvironment. Cancer Cell. (2012) 21:309-22. doi: 10.1016/j.ccr.2012.02.022

83. Pitt JM, Marabelle A, Eggermont A, Soria J-C, Kroemer G, Zitvogel L. Targeting the tumor microenvironment: removing obstruction to anticancer immune responses and immunotherapy. Ann Oncol. (2016) 27:1482-92. doi: 10.1093/annonc/mdw168

84. Pitt JM, Vétizou M, Daillère R, Roberti MP, Yamazaki T, Routy B, et al. Resistance mechanisms to immune-checkpoint blockade in cancer: tumor-intrinsic and -extrinsic factors. Immunity. (2016) 44:1255-69. doi: 10.1016/j.immuni.2016.06.001

85. Chang C-H, Pearce EL. Emerging concepts of T cell metabolism as a target of immunotherapy. Nat Immunol. (2016) 17:364-8. doi: 10.1038/ni.3415

86. Passarelli A, Tucci M, Mannavola F, Felici C, Silvestris F. The metabolic milieu in melanoma: role of immune suppression by CD73/adenosine. Tumour Biol. (2019) 42:1010428319837138. doi: 10.1177/1010428319837138

87. Fredholm BB, IJzerman AP, Jacobson KA, Klotz KN, Linden J. International Union of Pharmacology. XXV. Nomenclature and classification of adenosine receptors. Pharmacol Rev. (2001) 53:527-52. doi: 10.1124/pr.110.003285

88. Morello S, Pinto A, Blandizzi C, Antonioli L. Myeloid cells in the tumor microenvironment: role of adenosine. Oncoimmunology. (2015) 5:e1108515. doi: 10.1080/2162402X.2015.1108515

89. Iannone R, Miele L, Maiolino P, Pinto A, Morello S. Blockade of $\mathrm{A} 2 \mathrm{~b}$ adenosine receptor reduces tumor growth and immune suppression mediated by myeloid-derived suppressor cells in a mouse model of melanoma. Neoplasia. (2014) 15:1400-9. doi: 10.1593/neo.131748

90. Schnurr M, Toy T, Shin A, Hartmann G, Rothenfusser S, Soellner J, et al. Role of adenosine receptors in regulating chemotaxis and cytokine production of plasmacytoid dendritic cells. Blood. (2003) 103:1391-7. doi: 10.1182/blood-2003-06-1959

91. Yaku K, Okabe K, Hikosaka K, Nakagawa T. NAD metabolism in cancer therapeutics. Front Oncol. (2018) 8:622. doi: 10.3389/fonc.2018.00622

92. Audrito V, Managò A, La Vecchia S, Zamporlini F, Vitale N, Baroni G, et al. Nicotinamide Phosphoribosyltransferase (NAMPT) as a therapeutic 
target in BRAF-mutated metastatic melanoma. J Natl Cancer Inst. (2018) 110:290-303. doi: 10.1093/jnci/djx198

93. Rodriguez PC, Quiceno DG, Zabaleta J, Ortiz B, Zea AH, Piazuelo MB, et al. Arginase I production in the tumor microenvironment by mature myeloid cells inhibits T-cell receptor expression and antigen-specific T-cell responses. Cancer Res. (2004) 64:5839-49. doi: 10.1158/0008-5472.CAN-04-0465

94. Guirnalda P, Wood L, Goenka R, Crespo J, Paterson Y. Interferon $\gamma$-induced intratumoral expression of CXCL9 alters the local distribution of T cells following immunotherapy with Listeria monocytogenes. Oncoimmunology. (2013) 2:e25752. doi: 10.4161/onci.25752

95. Gajewski TF, Woo S-R, Zha Y, Spaapen R, Zheng Y, Corrales L, et al. Cancer immunotherapy strategies based on overcoming barriers within the tumor microenvironment. Curr Opin Immunol. (2013) 25:268-76. doi: 10.1016/j.coi.2013.02.009

96. Roberts EW, Broz ML, Binnewies M, Headley MB, Nelson AE, Wolf DM, et al. Critical role for CD103(+)/CD141(+) dendritic cells bearing CCR7 for tumor antigen trafficking and priming of $\mathrm{T}$ cell immunity in melanoma. Cancer Cell. (2016) 30:324-36. doi: 10.1016/j.ccell.2016.06.003

97. Spranger S, Spaapen RM, Zha Y, Williams J, Meng Y, Ha TT, et al. Up-regulation of PD-L1, IDO, and T(regs) in the melanoma tumor microenvironment is driven by CD8(+) T cells. Sci Transl Med. (2013) 5:200ra116. doi: 10.1126/scitranslmed.3006504

98. Greenfield EA, Nguyen KA, Kuchroo VK. CD28/B7 costimulation: a review. Crit Rev Immunol. (1998) 18:389-418. doi: 10.1615/CritRevImmunol.v18.i5.10

99. Ohshima Y, Tanaka Y, Tozawa H, Takahashi Y, Maliszewski C, Delespesse G. Expression and function of OX40 ligand on human dendritic cells. $J$ Immunol. (1997) 159:3838-48.

100. Gardner D, Jeffery LE, Sansom DM. Understanding the CD28/CTLA-4 (CD152) pathway and its implications for costimulatory blockade. Am J Transplant. (2014) 14:1985-91. doi: 10.1111/ajt.12834

101. Pardoll DM. The blockade of immune checkpoints in cancer immunotherapy. Nat Rev Cancer. (2012) 12:252-64. doi: 10.1038/nrc3239

102. Lee KM, Chuang E, Griffin M, Khattri R, Hong DK, Zhang W, et al. Molecular basis of T cell inactivation by CTLA-4. Science. (1998) 282:2263-6 doi: 10.1126/science.282.5397.2263

103. Versteven M, Van den Bergh JMJ, Marcq E, Smits ELJ, Van Tendeloo VFI, Hobo W, et al. Dendritic cells and programmed death-1 blockade: a joint venture to combat cancer. Front Immunol. (2018) 9:394. doi: 10.3389/fimmu.2018.00394

104. Wang XB, Fan ZZ, Anton D, Vollenhoven AV, Ni ZH, Chen XF, et al. CTLA4 is expressed on mature dendritic cells derived from human monocytes and influences their maturation and antigen presentation. BMC Immunol. (2011) 12:21. doi: 10.1186/1471-2172-12-21

105. Reschner A, Hubert $\mathrm{P}$, Delvenne $\mathrm{P}$, Boniver J, Jacobs $\mathrm{N}$. Innate lymphocyte and dendritic cell cross-talk: a key factor in the regulation of the immune response. Clin Exp Immunol. (2008) 152:219-26. doi: 10.1111/j.1365-2249.2008.03624.x

106. Frederick DT, Piris A, Cogdill AP, Cooper ZA, Lezcano C, Ferrone $\mathrm{CR}$, et al. BRAF inhibition is associated with enhanced melanoma antigen expression and a more favorable tumor microenvironment in patients with metastatic melanoma. Clin Cancer Res. (2013) 19:1225-31. doi: 10.1158/1078-0432.CCR-12-1630

107. Cafforio P, Savonarola A, Stucci S, De Matteo M, Tucci M, Brunetti AE, et al. PTHrP produced by myeloma plasma cells regulates their survival and proosteoclast activity for bone disease progression. J Bone Miner Res. (2013) 29:55-66. doi: 10.1002/jbmr.2022

108. Patel JM, Dale GA, Vartabedian VF, Dey P, Selvaraj P. Cancer CARtography: charting out a new approach to cancer immunotherapy. Immunotherapy. (2014) 6:675-8. doi: 10.2217/imt.14.44

109. Simon T, Bromberg JS. BTLA+ dendritic cells: the regulatory T cell force awakens. Immunity. (2016) 45:956-8. doi: 10.1016/j.immuni.2016.10.030

110. Gardner A, Ruffell B. Dendritic cells and cancer immunity. Trends Immunol. (2016) 37:855-65. doi: 10.1016/j.it.2016.09.006

111. Tucci M, Passarelli A, Mannavola F, Stucci LS, Ascierto PA, Capone $\mathrm{M}$, et al. Serum exosomes as predictors of clinical response to ipilimumab in metastatic melanoma. Oncoimmunology. (2017) 7:e1387706. doi: 10.1080/2162402X.2017.1387706
112. Halpert MM, Konduri V, Liang D, Chen Y, Wing JB, Paust S, et al. Dendritic cell-secreted cytotoxic T-lymphocyte-associated protein-4 regulates the Tcell response by downmodulating bystander surface B7. Stem Cells Dev. (2016) 25:774-87. doi: 10.1089/scd.2016.0009

113. Chae YK, Arya A, Iams W, Cruz MR, Chandra S, Choi J, et al. Current landscape and future of dual anti-CTLA4 and PD-1/PD-L1 blockade immunotherapy in cancer; lessons learned from clinical trials with melanoma and non-small cell lung cancer (NSCLC). J Immunother Cancer. (2018) 6:39. doi: 10.1186/s40425-018-0349-3

114. Pulko V, Liu X, Krco CJ, Harris KJ, Frigola X, Kwon ED, et al. TLR3stimulated dendritic cells up-regulate B7-H1 expression and influence the magnitude of CD8 T cell responses to tumor vaccination. J Immunol. (2009) 183:3634-41. doi: 10.4049/jimmunol.0900974

115. Schreiber HA, Hulseberg PD, Lee J, Prechl J, Barta P, Szlavik N, et al. Dendritic cells in chronic mycobacterial granulomas restrict local antibacterial T cell response in a murine model. PLOS ONE. (2010) 5:e11453. doi: 10.1371/journal.pone.0011453

116. Francisco LM, Salinas VH, Brown KE, Vanguri VK, Freeman GJ, Kuchroo VK, et al. PD-L1 regulates the development, maintenance, and function of induced regulatory T cells. J Exp Med. (2009) 206:3015-29. doi: 10.1084/jem.20090847

117. Benson DM, Bakan CE, Mishra A, Hofmeister CC, Efebera Y, Becknell $\mathrm{B}$, et al. The PD-1/PD-L1 axis modulates the natural killer cell versus multiple myeloma effect: a therapeutic target for CT-011, a novel monoclonal anti-PD-1 antibody. Blood. (2010) 116:2286-94. doi: 10.1182/blood-2010-02-271874

118. Iraolagoitia XLR, Spallanzani RG, Torres NI, Araya RE, Ziblat A, Domaica $\mathrm{CI}$, et al. NK cells restrain spontaneous antitumor CD8 $+\mathrm{T}$ cell priming through PD-1/PD-L1 interactions with dendritic cells. J Immunol. (2016) 197:953-61. doi: 10.4049/jimmunol.1502291

119. Long L, Zhang X, Chen F, Pan Q, Phiphatwatchara P, Zeng Y, et al. The promising immune checkpoint LAG-3: from tumor microenvironment to cancer immunotherapy. Genes Cancer. (2019) 9:176-89. doi: 10.18632/genesandcancer.180

120. Chevalier MF, Bohner P, Pieraerts C, Lhermitte B, Gourmaud J, Nobile A, et al. Immunoregulation of dendritic cell subsets by inhibitory receptors in urothelial cancer. Eur Urol. (2016) 71:854-7. doi: 10.1016/j.eururo.2016.10.009

121. Zhu C, Anderson AC, Schubart A, Xiong H, Imitola J, Khoury SJ, et al. The Tim-3 ligand galectin-9 negatively regulates T helper type 1 immunity. Nat Immunol. (2005) 6:1245-52. doi: 10.1038/ni1271

122. Ngiow SF, Teng MWL, Smyth MJ. Prospects for TIM3-targeted antitumor immunotherapy. Cancer Res. (2011) 71:6567-71. doi: 10.1158/0008-5472.CAN-11-1487

123. Muller WA. The role of PECAM-1 (CD31) in leukocyte emigration: studies in vitro and in vivo. J Leukoc Biol. (1995) 57:523-8. doi: 10.1002/jlb.57.4.523

124. Muller WA, Weigl SA, Deng X, Phillips DM. PECAM-1 is required for transendothelial migration of leukocytes. J Exp Med. (1993) 178:449-60. doi: 10.1084/jem.178.2.449

125. Ma L, Mauro C, Cornish GH, Chai J-G, Coe D, Fu H, et al. Ig genelike molecule CD31 plays a nonredundant role in the regulation of $\mathrm{T}$ cell immunity and tolerance. Proc Natl Acad Sci USA. (2010) 107:19461-6. doi: 10.1073/pnas.1011748107

126. Clement M, Fornasa G, Guedj K, Mkaddem SB, Gaston A-T, KhallouLaschet J, et al. CD31 is a key coinhibitory receptor in the development of immunogenic dendritic cells. Proc Natl Acad Sci USA. (2014) 111:E1101-10. doi: 10.1073/pnas.1314505111

127. Tucci M, Ciavarella S, Strippoli S, Brunetti O, Dammacco F, Silvestris F. Immature dendritic cells from patients with multiple myeloma are prone to osteoclast differentiation in vitro. Exp Hematol. (2011) 39:773-83.e1. doi: 10.1016/j.exphem.2011. 04.006

128. Anderson DM, Maraskovsky E, Billingsley WL, Dougall WC, Tometsko ME, Roux ER, et al. A homologue of the TNF receptor and its ligand enhance T-cell growth and dendritic-cell function. Nature. (1997) 390:175-9. doi: $10.1038 / 36593$

129. Ahern E, Smyth MJ, Dougall WC, Teng MWL. Roles of the RANKLRANK axis in antitumour immunity - implications for therapy. 
Nat Rev Clin Oncol. (2018) 15:676-93. doi: 10.1038/s41571-0180095-y

130. Arab S, Kheshtchin N, Ajami M, Ashurpoor M, Safvati A, Namdar A, et al. Increased efficacy of a dendritic cell-based therapeutic cancer vaccine with adenosine receptor antagonist and CD73 inhibitor. Tumour Biol. (2017) 39:1010428317695021. doi: 10.1177/1010428317695021

131. Rizvi NA, Hellmann MD, Snyder A, Kvistborg P, Makarov V, Havel JJ, et al. Cancer immunology. Mutational landscape determines sensitivity to PD-1 blockade in non-small cell lung cancer. Science. (2015) 348:124-8. doi: 10.1126/science.aaa1348

132. Tumeh PC, Harview CL, Yearley JH, Shintaku IP, Taylor EJM, Robert L, et al. PD-1 blockade induces responses by inhibiting adaptive immune resistance. Nature. (2014) 515:568-71. doi: 10.1038/nature13954

133. Spranger $S$, Bao $R$, Gajewski TF. Melanoma-intrinsic $\beta$-catenin signalling prevents anti-tumour immunity. Nature. (2015) 523:231-5. doi: 10.1038/nature14404

134. Salmon H, Idoyaga J, Rahman A, Leboeuf M, Remark R, Jordan S, et al. Expansion and activation of CD103(+) dendritic cell progenitors at the tumor site enhances tumor responses to therapeutic PD-L1 and BRAF inhibition. Immunity. (2016) 44:924-38. doi: 10.1016/j.immuni.2016.03.012

135. Kuske M, Westphal D, Wehner R, Schmitz M, Beissert S, Praetorius $\mathrm{C}$, Meier F. Immunomodulatory effects of BRAF and MEK inhibitors: implications for melanoma therapy. Pharmacol Res. (2018) 136:151-9. doi: 10.1016/j.phrs.2018.08.019

136. Ott PA, Henry T, Baranda SJ, Frleta D, Manches O, Bogunovic D, et al. Inhibition of both BRAF and MEK in BRAF(V600E) mutant melanoma restores compromised dendritic cell (DC) function while having differential direct effects on DC properties. Cancer Immunol Immunother. (2013) 62:811-22. doi: 10.1007/s00262-012-1389-z

137. Wilmott JS, Long GV, Howle JR, Haydu LE, Sharma RN, Thompson JF, et al. Selective BRAF inhibitors induce marked T-cell infiltration into human metastatic melanoma. Clin Cancer Res. (2011) 18:1386-94. doi: 10.1158/1078-0432.CCR-11-2479
138. de Andrade LF, Ngiow SF, Stannard K, Rusakiewicz S, Kalimutho M, Khanna KK, et al. Natural killer cells are essential for the ability of BRAF inhibitors to control BRAFV600E-mutant metastatic melanoma. Cancer Res. (2014) 74:7298-308. doi: 10.1158/0008-5472.CAN-14-1339

139. Tel J, Koornstra R, de Haas N, van Deutekom V, Westdorp H, Boudewijns $\mathrm{S}$, et al. Preclinical exploration of combining plasmacytoid and myeloid dendritic cell vaccination with BRAF inhibition. J Transl Med. (2016) 14:88. doi: 10.1186/s12967-016-0844-6

140. Steinberg SM, Turk MJ. BRAF-inhibition and tumor immune suppression. Oncoimmunology. (2015) 4:e988039. doi: 10.4161/2162402X.2014.988039

141. Teng MWL, Ngiow SF, Ribas A, Smyth MJ. Classifying cancers based on T-cell infiltration and PD-L1. Cancer Res. (2015) 75:2139-45. doi: 10.1158/0008-5472.CAN-15-0255

142. Galon J, Lugli A, Bifulco C, Pages F, Masucci G, Marincola FM, et al. Worldwide immunoscore task force: meeting report from the "Melanoma Bridge", Napoli, November 30th-December 3rd, 2016. J Transl Med. (2017) 15:212. doi: 10.1186/s12967-017-1310-9

143. Pages F, Mlecnik B, Marliot F, Bindea G, Ou F-S, Bifulco C, et al. International validation of the consensus Immunoscore for the classification of colon cancer: a prognostic and accuracy study. Lancet. (2018) 391:2128-39. doi: 10.1016/S0140-6736(18)30789-X

Conflict of Interest: The authors declare that the research was conducted in the absence of any commercial or financial relationships that could be construed as a potential conflict of interest.

Copyright (C) 2019 Tucci, Passarelli, Mannavola, Felici, Stucci, Cives and Silvestris. This is an open-access article distributed under the terms of the Creative Commons Attribution License (CC BY). The use, distribution or reproduction in other forums is permitted, provided the original author(s) and the copyright owner(s) are credited and that the original publication in this journal is cited, in accordance with accepted academic practice. No use, distribution or reproduction is permitted which does not comply with these terms. 